\section{Observed versus predicted hospital mortality in general wards patients assisted by a medical emergency team}

\author{
LUCA CABRINI • GIACOMO MONTI •VALENTINA PAOLA PLUMARI • \\ GIOVANNI LANDONI•STEFANO TURI•PASIN LAURA•PAOLO SILVANI • \\ SERGIO COLOMBO•ALBERTO ZANGRILLO
}

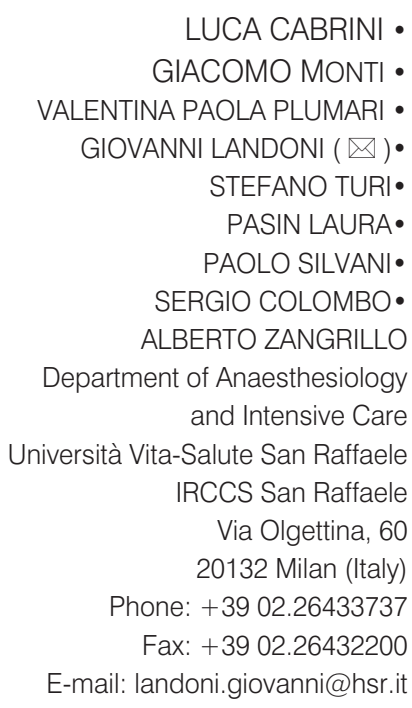

LUCA CABRINI •

GIACOMO MONTI •

VALENTINA PAOLA PLUMARI • GIOVANNI LANDONI $(\square) \bullet$ STEFANO TURI $\bullet$ PASIN LAURA• PAOLO SILVANI• SERGIO COLOMBO• ALBERTO ZANGRILLO

Department of Anaesthesiology and Intensive Care Università Vita-Salute San Raffaele IRCCS San Raffaele

Via Olgettina, 60

20132 Milan (Italy)

Phone: +3902.26433737

Fax: +3902.26432200

E-mail: landoni.giovanni@hsr.it

\begin{abstract}
Introduction. In many countries the demand for intensive care beds exceeds their availability. The Medical Emergency Team (MET) can manage critically ill patients outside the intensive care unit (ICU). Hospital mortality rate for patients admitted to general wards and assisted by the MET was never compared to the predicted mortality for the same group of patients in an ICU setting.

Methods. Single-centre, prospective, observational study on consecutive adult patients assisted by the MET in all general wards and in the Emergency Department of a 1100-bed teaching Hospital. Patients with a 'do-not-attempt-resuscitation' decision were excluded.

Results. Eighty-two consecutive patients were included. Observed hospital mortality was $34.1 \%$ (28 patients), while the Simplified Acute Physiology Score II (SAPS II) predicted a mortality for the first MET visit of $17 \%(p=0.02)$. Patients transferred to an ICU, but not during the first MET evaluation (delayed ICU admission), had worse than predicted outcomes, while patients immediately transferred to an ICU showed hospital mortality similar to the predicted one. The fifty patients treated for acute respiratory failure (especially those with pneumonia - 12 patients) had the worst observed/predicted hospital mortality ratio (3.0 for acute respiratory failure, $p=0.02 ; 8.06, p=0.03$ for pneumonia patients).

Conclusions. Critically ill patients who remained in general wards or who were admitted to the ICU with some delay had markedly higher hospital mortality than the SAPS II predicted hospital mortality, even if they were assisted by the MET.
\end{abstract}

Key words: medical emergency team, rapid response system, intensive care unit; critical care

\section{Introduction}

In many countries the demand for intensive care beds exceeds their availability, (1-3) and it is unlikely that the number of expensive Intensive Care Unit (ICU) beds will increase. Earlier and better selection of patients admitted to ICU can allow more appropriate utilization of available intensive care resources.
(4-5) However, correctly referred patients frequently cannot be admitted to ICU due to triaging considerations. $(1,6,7)$ As a consequence, critically ill patients are hospitalized outside the ICU: some evidence exists that these patients have a mortality rate higher than similar patients admitted to ICU, $(1-3,8)$ although a recent study did not confirm the data. (9)

Among the different "responding teams", the Medical Emergency Team (MET) is the best evaluated: (10) nonet- heless, its efficacy -and the methods to ascertain it- remains a matter of discussion. $(11,12)$ No study compared the outcome of patients assisted in ordinary wards by the MET to the expected outcome for the same patients if admitted to ICU.

To verify MET efficacy as compared to ICU performance, we compared hospital mortality of general ward patients assisted by the MET to the SAPS II (13) predicted mortality for the same patients in an ICU setting. 


\section{Materials and Methods}

After local Ethical Committee approval, we performed a single-centre, prospective, observational study on all consecutive patients treated by the MET over a 2-month period in a 1100-bed teaching hospital. Exclusion criteria were represented by a Do-Not-Attempt-Resuscitation (DNAR) decision taken before or after the MET call, age < 18 years; acute condition developed in an intermediate unit. Our MET is described elsewhere (14): it was introduced more than 20 years ago and is dedicated to patients in the Emergency Department or in the wards. Briefly, the MET shift is carried out by anaesthesiologists, who in Italy act also as intensivists; no strict criteria to alert the MET are in use.

Demographic data and pre-existing diseases were collected together with the diagnosis of the acute event, patients' vital signs at MET arrival and at the end of the MET's first visit and SAPS II score.
On the basis of patients' conditions, wards' expertise and capabilities in managing critically ill patients, and availability of ICU beds, the MET decided at the end of its first evaluation to leave the patient on the ward or to transfer the patient to ICU ("early ICU transfer"). Survivors not immediately transferred to ICU had follow-up visits. Some of them required subsequent ICU transfer (defined "late ICU transfer").

Statistical methods. Data were collected by Microsoft Access $₫$ and statistical analysis performed by SPSS 15.0 or Microsoft Excel ${ }^{\circledR}$. Continuous variables were expressed as mean (SD) or median (interquartile range) as appropriate. Univariate analysis was performed with the Student's T test or the Mann-Whitney $U$ test as appropriate. Comparison among SAPS II predicted mortality and observed mortality was done by Z proportion - test. Confidence Intervals $(\mathrm{Cl})$ are at $95 \%$ probability.

\section{Results}

Eighty-two consecutive patients were enrolled, all completed the follow-up. Half of the patients (53\%) were initially evaluated in the Emergency Department. SAPS II mean value was 25 (2135), with no difference between survivors and non survivors; no difference was observed either for vital signs (systolic and diastolic arterial blood pressure, heart and respiratory rate, pulse oxymetry values). On average, patients had $3 \pm 1$ co-morbidities (table 1). Table 2 shows the diagnosis recorded at the end of the MET's first evaluation; $61 \%$ of patients presented with acute respiratory failure.

MET first evaluation ended with a patient's death in 2 (2.4\%) cases and early ICU transfer in 15 (18.3\%) cases, while no patient was transferred to an intermediate unit. Sixty-seven (81.7\%) patients remained in the same ward with 15 of them having a late ICU transfer.

Table 1. Demographics and baseline characteristics of the study population.

\begin{tabular}{lcccc}
\hline Variable & Total & Alive & Dead & p-value \\
\hline Male & $\mathbf{N = 8 2}$ & $\mathbf{N = 5 4 ( 6 5 . 9 \% )}$ & $\mathbf{N = 2 8 ~ ( 3 4 . 1 \% )}$ & 0.412 \\
\hline Age & $48(58.5 \%)$ & $28(51.9 \%)$ & $20(71.4 \%)$ & 0.932 \\
\hline Days from hospital admission to MET first visit & $66 \pm 16.9$ & $65 \pm 16.5$ & $65 \pm 17.3$ & 0.576 \\
\hline Co-morbidities & $5(2-14)$ & $4(2-8)$ & $6(2-25)$ & \\
\hline Arterial hypertension & & & & 0.612 \\
\hline Ischemic heart disease & $38(46.3 \%)$ & $26(48.1 \%)$ & $12(42.9 \%)$ & 0.258 \\
\hline Endocrine diseases & $24(29.3 \%)$ & $12(22.2 \%)$ & $12(42.9 \%)$ & 0.659 \\
\hline Central nervous system disease & $24(29.3) \%$ & $15(27.8 .3 \%)$ & $9(32.1 \%)$ & 0.615 \\
\hline Chronic obstructive pulmonary disease & $19(23.2 \%)$ & $13(24.1 \%)$ & $6(21.4 \%)$ & 0.438 \\
\hline Arrhythmia & $18(22.0 \%)$ & $14(25.9 \%)$ & $4(14.3 \%)$ & 0.193 \\
\hline Cancer & $18(22.0 \%)$ & $8(14.8 \%)$ & $10(35.7 \%)$ & 0.672 \\
\hline Congestive heart failure & $18(22.0 \%)$ & $11(20.4 \%)$ & $7(25.0 \%)$ & 0.144 \\
\hline Renal failure & $17(20.7 \%)$ & $7(13.0 \%)$ & $17(60.7 \%)$ & 9.251 \\
\hline Coagulopathy or oral anticoagulation & $17(20.7 \%)$ & $8(14.8 \%)$ & $9(32.1 \%)$ & $6(21.4 \%)$ \\
\hline Hematologic diseases & $10(12.2 \%)$ & $4(7.4 \%)$ & 0.235 \\
\hline Lung restrictive disease & $7(8.5 \%)$ & $2(3.7 \%)$ & $5(17.9 \%)$ & 0.157 \\
\hline Liver failure & $7(8.5 \%)$ & $0(0.0 \%)$ & $7(25.0 \%)$ & 0.411 \\
\hline Bone marrow or solid organ transplant & $4(4.9 \%)$ & $3(5.6 \%)$ & $1(3.6 \%)$ & 0.619 \\
\hline Other & $2(2.4 \%)$ & $0(0.0 \%)$ & $2(7.1 \%)$ & 0.184 \\
\hline
\end{tabular}

Legend. Data are expressed as number (\%), mean \pm SD or median (interquartile range). Percent refers to the total amount of patients in each column. P-values refers to X squared, T-or U-test as appropriate. 
Observed hospital mortality was $34.1 \%$, 95\% Cl: $23.8-44.4 \%$, while the SAPS II predicted mortality was $17 \%(p=0.02)$ (table 3). Early ICU transfers had similar $(p=0.9)$ observed $(40 \%)$ and SAPS II predicted (41\%) mortality. Late ICU transfers had a higher mortality rate $(60 \%)$ than the SAPS II predicted one (18\%). Most patients were never transferred to an ICU and had a hospital mortality of $33 \%$ versus a predicted one of $10 \%(p=0.03)$.

Acute respiratory failure was associated with a higher than predicted risk of death (ratio $3, p=0.02$ ), with pneumonia patients having an increase in ratio up to $8(p=0.03)$. The study took place at the end of 2007: at our institution the average ICU bed occupancy for that year was $95.9 \%$.

\section{Discussion}

The present study compares, for the first time, the observed and expected mortality in patients managed by a MET. We found a significantly higher than predicted mortality in patients who were not immediately transferred to the ICU In our study we collected SAPS II values of all MET patients and compared their hospital outcome to the supposed best possible scenario for critically ill

Table 2. Main diagnosis at the end of Medical Emergency Team first evaluation.

\begin{tabular}{ll}
\hline Diagnosis & N (\%) \\
\hline Respiratory failure & $50(61.0 \%)$ \\
\hline Pneumonia & $12(24 \%)$ \\
\hline Chronic obstructive pulmonary disease exacerbation & $7(14 \%)$ \\
\hline Others & $31(62 \%)$ \\
\hline Non-respiratory failure diagnosis & $32(39.0 \%)$ \\
\hline Trauma & $8(25 \%)$ \\
\hline central nervous system disease & $7(21.9 \%)$ \\
\hline Hemorrhagic shock & $6(18.8 \%)$ \\
\hline Septic shock & $4(12.5 \%)$ \\
\hline Cardiogenic shock & $3(9.4 \%)$ \\
\hline Other & $4(12.5 \%)$ \\
\hline
\end{tabular}

patients (the hospital mortality for patients admitted to an ICU). The observed excess mortality was alarming.

High mortality rates among critically ill patients hospitalised outside ICU have already been reported, but comparison with SAPS II expected mortality was never performed. Metcalfe et al. (8) suggested a high mortality rate if admission to ICU was denied due to logistic causes. Joynt et al. (1) found an excess mortality for patients who were denied ICU admission, particularly in the middle range of illness severity: a high (60\%) mortality was also observed in delayed ICU transfers. Hersch (9) did not report deaths within $48 \mathrm{~h}$ in patients considered for, but not admitted to, the ICU; however, $9 \%$ of these patients needed admission to ICU within 48h. Time matters when caring for critically ill patients. The negative effect of ICU admission delay on survival was demonstrated by Duke et al. (15) in 619 consecutive ICU admissions.

Delay in calling the MET can affect the MET's ability in lowering the mortality in critically ill patients, $(16,17)$ but the results of our study were not influenced by what preceded MET activation, as SAPS II was recorded at the MET's first visit, without considering if patient deterioration could have been be intercepted earlier. On the contrary, the

Table 3. Observed mortality and SAPS II predicted mortality in patients' subgroups. Ratio refers to observed over predicted values. P-value refers to $Z$ test for proportion comparison.

\begin{tabular}{lllllll}
\hline Category & $\mathrm{N}$ & dead & $\begin{array}{l}\text { Mortality } \% \\
\mathbf{( \pm 9 5} \mathbf{C l})\end{array}$ & $\begin{array}{l}\text { SAPS II } \\
\text { mean } \pm \text { SD }\end{array}$ & $\begin{array}{l}\text { mortality } \\
\text { ratio }\end{array}$ & p-values \\
\hline Emergency department as first visit location & 52 & 16 & $31 \pm 12.5$ & $36 \pm 17.2$ & 1.06 & 0.25 \\
\hline Early ICU transfer & 15 & 6 & $40 \pm 24.8$ & $27 \pm 12.2$ & 1.00 & 0.9 \\
\hline Late ICU transfer & 15 & 9 & $60 \pm 24.8$ & $33 \pm 11.8$ & 3.03 & 0.05 \\
\hline Never transferred to ICU & 40 & 13 & $33 \pm 14.5$ & $26 \pm 11.9$ & 3.25 & 0.03 \\
\hline Respiratory failure & 50 & 15 & $30 \pm 12.7$ & $27 \pm 9.1$ & 3.00 & 0.02 \\
\hline Pneumonia & 12 & 7 & $58 \pm 27.9$ & $25 \pm 4.6$ & 8.06 & 0.03 \\
\hline Chronic obstructive pulmonary disease exacerbation & 7 & 0 & 0.00 & $22 \pm 5.7$ & 0.00 & 0.9 \\
\hline Diagnosis other than respiratory failure & 32 & 13 & $41 \pm 17.0$ & $36 \pm 22.3$ & 1.04 & 0.5 \\
\hline $\begin{array}{l}\text { Total study group (including 2 patients dead during the first } \\
\text { MET visit) }\end{array}$ & \multirow{2}{*}{28} & 28 & $34 \pm 10.3$ & $30 \pm 16.1$ & 2.00 & 0.02 \\
\hline
\end{tabular}

Abbreviations

$\mathrm{N}$ : number of patients

ICU: intensive care unit 
ability of the wards to care for critically ill patients after MET activation, and in conjunction with the MET, strongly influenced patients' outcome. An increase in hospital mortality in patients receiving multiple MET visits has recently been reported. (18)

Patients admitted immediately to the ICU, and managed by the same anaesthesiologists on the MET shift, had survival rates in accordance with the SAPS II predicted values, so the "quality" of the "efferent limb" does not seem to be relevant in explaining the high observed mortality.

In our experience, the anaesthesiologist on the general wards did not perform as well as in the ICU: the environment (quality and frequency of monitoring, number and training of nurses, equipment, speed in diagnostic and therapeutic actions, senior supervision, etc.) made the difference. The MET can be inefficient if other parts of the rapid response systems (RRS) are inadequate; as suggested by our results, the number of intensive care beds should be considered a part of the RRS

Due to the shortage of intensive care beds, triage decisions are an everyday occurrence. Prioritization criteria have been defined to help select patients who are most likely to benefit from ICU care. (4) Nevertheless, definition and evaluation of triage recommendations have never considered the potentially positive role of the MET. When cared for by the MET, critically ill patients can have different outcomes based on their specific disease or characteristics, so their need for an ICU bed can differ. In our study, acute respiratory failure (particularly if due to pneumonia) seemed to be associated with a higher mortality rate, despite MET assistance. MET applying NIV outside the ICU (19) should be well aware of the potential danger of delaying ICU admission in pneumonia patients: a careful monitoring is required.

Limitations. The study was mono-centric and data collection was limited to a two-month period. We did not record data on ward staff ability (or willingness) to apply the recommendations made by the MET: in our experience, as in others, (20) the MET stayed with the patients a limited time, leaving to ward staff the burden of following his/ her orders. We did not collect data on ICU bed occupancy at the time when patients were evaluated by the MET, nor did we collect data on how often the MET requested or desired to transfer a patient to the ICU. Intensivists involved in the MET shift, usually worked in the ICU as well, and they were well aware of the shortage of ICU beds and of the need to triage critically ill patients. So MET requests to admit patients could be misleading, underestimating the number of patients that the MET would have transferred to the ICU. In a similar way, Simchen (2) showed as under a chronic shortage of intensive beds ward staff requested admission to ICU only for a half of the critically ill patients.

\section{Conclusions}

In the setting of a chronic shortage of available ICU beds, critically ill patients not admitted early to the ICU had a hospital mortality higher than the SAPS II predicted value for an ICU setting, especially if they had acute respiratory failure due to pneumonia. The number of ICU beds should be considered part of the RRS. 


\section{ACKNOWLEDGMENTS}

We are grateful to all our colleagues who covered the MET shift and co-operated in the study. We would also like to thank Mrs Louise Wheelan, RN, for her valuable support.

\section{REFERENCES}

1. Joynt GM, Gomersall CD, Tan P, Lee A, et al. Prospective evaluation of patients refused admission to an intensive care unit: triage, futility and outcome. Intensive Care Med 2001;27:1459-65.

2. Simchen E, Sprung CL, Galai N, Zitser-Gurevich Y, et al. Survival of critically ill patients hospitalized in and out of intensive care unit beds. Crit Care Med 2004; 32:1654-61.

3. Mnatzaganian G, Sprung CL, Zitser-Gurevich Y, Galai N, et al. Effect of infections on 30-day mortality among critically ill patients hospitalized in and out of the intensive care unit. Crit Care Med 2008;36:1097-04.

4. American College of Critical Care Medicine of the Society of Critical care Medicine: Guidelines for ICU admission, discharge and triage. Crit Care Med 1999;27:633-8.

5. Savoia G, Bosco G, Cerchiari E, De Blasio E, et al. for SIAARTI - IRC Working Group: SIAARTI-IRC: Recommendations for organizing responses to in-hospital emergencies. Minerva Anestesiol 2007;73:533-53.

6. Strauss MJ, LoGerefo JP, Yeltatzie JA, Temkin N, et al: Rationing of intensive care unit services. An everyday occurrence. JAMA 1986;255:1143-6.

7. Singer DE, Carr PL, Mulley AG, Thibault GE. Rationing intensive care-physician responses to a resource shortage. N Engl J Med 1983;309:1155-60

8. Metcalfe MA, Slogget A, McPherson K. Mortality among appropriately referred patients refused admission to intensive-care units. Lancet 1997;350:7-11.

9. Hersch M, Sonnenblick M, Vanhecke T, Gandhi M, McCullough PA, Lazar MH, et al. Outcomes of patients refused considered for, but not admitted to, the intensive care unit. Crit Care Med 2008;36:812-7.

10. DeVita M, Bellomo R, Hillman K, Kellum J, et al. Findings of the First Consensus Conference on Medical Emergency Teams. Crit Care Med 2006;34:2463-78

11. Winters BD, Cuong Pam J, Hunt EA, Guallar E, et al.. Rapid response systems. A systematic review. Crit Care Med 2007;35:1238-43.

12. DeVita MA, Bellomo R. The case of rapid response systems: Are randomized clinical trials the right methodology to evaluate systems of care? Crit Care Med 2007;35:1413-4

13. Le Galle JR, Lemeshow S , Saulnier F. A new Simplified Acute Physiology Score (SAPS II) based on a European/North American multicenter study. JAMA1993; ?: 22-9.

14. Cabrini L, Idone C, Colombo S et al. Medical Emergency Team and non-invasive ventilation outside ICU for acute respiratory failure. Intensive Care Med 2009;35:333-43.

15. Duke G, Green J, Briedis J. Survival of critically ill medical patients is time-critical. Crit Care Resusc 2004;6:261-7.

16. Mitchell IA, McKay H, Van Leuvan $\mathrm{C}$ et al. A prospective controlled trial of the effect of a multi-faceted intervention on early recognition and intervention in deteriorating hospital patients. Resuscitation 2010;81:658-66.

17. Tee A, Calzavacca P, Licari E, Goldsmith D, et al. Bench-to-bedside review: the MET syndrome - the challenges of researching and adopting medical emergency teams. Crit Care 2008;12:205doi:10.1186/cc6199.

18. Calzavacca P, Licari E, Tee A et al. Features and outcome of patients receiving multiple Medical Emergency team reviews. Resuscitation 2010;81:1509-15.

19. Cabrini L, Antonelli M, Savoia G, Landriscina M. Non-invasive ventilation outside of the Intensive Care Unit: an Italian survey. Minerva Anestesiol. 2011;77:313-22.

20. Flabouris A, Chen J, Hillman K et al. Timing and interventions of emergency teams during the MERIT study. Resuscitation 2010;81:25-30. 